accountable for these troubles. On the 6th the opium was discontinued (one and a half minims of tincture of digitalis being substituted). The infant then became brighter and cried more after its discontinuance. On the 7 th I again saw the patient with Dr. Munro. OEdema was at that time a marked feature though less extensive than it had been. The erythema had disappeared. The urine contained two parts per 1000 of albumin but there were no casts; it was slightly alkaline when passed and deposited a slight precipitate of earthy phosphates. Dr. Munro subsequently examined the urine and came to the conclusion that there was no deficiency of chlorides. Dr. Munro reported on the 11th that the oedema had quite disappeared since omitting the laudanum. Magnesium sulphate, 0.5 per cent., was now used by him for lavage with the idea that the magnesium base would assist in the elimination of chlorides. Starting on June 8th the child was fed on "humanoid" milk, an Aylesbury dairy company product. He took it well but only in small quantities; 15 grains of cane sugar were added to each feed. He appeared to be more satisfied with the new diet, and he slept well, but the weight fell to 5 pounds $12 \frac{1}{2}$ new diet, and he slept well, but the weight fell to 5 pounds $12 \frac{1}{2}$ every 36 hours in place of every 24 hours, as was previously the every 36 hours in place of every 24 hours, as was previously the
case. On the 14th Dr. Munro reported that the patient was case. On the 14th Dr. Munro reported that the patient was more than two ounces per feed." He was still losing weight, having dropped to 5 pounds 7 ounces-less than ever. He was sick while being fed once, the first time for a week, there having been no sickness since the 7 th. He was ordered a milk-and-water mixture-one part milk and two parts water-erery two and a half hours, from two to three ounces at a feed, and to three of the bottles a teaspoonful of eream was added. On the 15 th, as the mother was anxious for it, a wet nurse was obtained and mixed feeding was instituted. The infant was sick once on the 16th and three times on the 18th; on this latter occasion coffee-ground vomit occurred, which was thought to be due to cracked nipples. The wet nurse not being a success was discontinued. Lavage was discontinued on the 20th. The child was sick once on the 21st, but not again until the 28th, when he was sick once and then for the last time. had lost and gained on an average an ounce a day. He suffered a good deal with flatulence all through the illness, especially after food, and sometimes would cry nearly all day, as if in pain. (After wearing a woollen truss, which was applied in the midale of August, he cried ever so much less.) He perspired a

The weight of the patient on June $14 \mathrm{th}$, when milk-and-water feeding was started, was 5 pounds 7 ounces, and on July 8 th it was 6 pounds 12 ounces. Dav by day increasing quantities of milk-andwater were taken; on June 14 th the amount was 18 ounces, while on
July 6th it was 30 ounces. While on whey the bowels were opened once daily and the motions were green but after the child had been fed on milk and water for a week the stools became quite natural and there were from two to four motions in the 24 hours. Week by week the patient continued to gain ground and by July 27th, when the rectal injections of olive oil were discontinued, he weighed 8 pounds 1 ounce. On August 22nd, when brought back to London, he weighed 9 pounds 8 ounces, and on the $27 \mathrm{th}$, when the nurse left, he weighed 10 pounds and was steadily graining ground every day. In the middlo of September he suffered from spongy tender cums for a week but since impresing the necessity for antion since impressing the necessity for antiscorbutic foods upon the parents 16 pounds at seven and a half months and was a jolly, normal baby, and he still (January, 1908) continues to thrive.

\section{A SUGGESTION FOR TREATMENT IN DELAYED CHLOROFORM POISONING.}

By A. P. BEDDARD, M.A., M.D. CANTAB., F.R.C.P. LoND, ASSISTANT PHYSICIAN TO GUY'S HOSPITAL; PHYSICIAN TO THE WEGT LONDON HOSPITAL.

AlThougH patients suffering from delayed chloroform poisoning may recover spontaneously the literature of the subject shows that the prognosis is bad, which is only another way of saying that the treatment, whether preventive or curative, is unsatisfactory. The clinical symptoms and post-mortem appearances are constant and well established, but their interpretation is still a matter of controversy. Nevertheless, for the purposes of treatment it is necessary to adopt some working hypothesis of the pathology of the condition.

The curative treatment most frequently adopted has apparently been the use of alkalies. This presupposes that an acute acid intoxication of the body is at least an important cause of the symptoms and fatal result. And we must consider whether this is likely to be true. There are many conditions known in which metabolism is so deranged that organic acids produced in the body escape oxidation and are excreted in abnormal quantities in the urine. This state of things is termed acidosis. The body has to provide bases in order to neutralise these acids, and for this purpose it uses either $\mathrm{NH}_{3}$, the normal precursor of urea, or failing a sufficient supply of $\mathrm{NH}_{3}$ the inorganic bases in the tissues. The organic acids, such as lactic, $\beta$ oxybutyric, diacetic, \&c., which are intermediate products of metabolism, are not in themselves poisonous; their power of doin the body harm is confined to their action as acids and as long as the body provides sufficient base to neutralise them their presence will not produce symptoms. In other words, acidosis is not a poisoning of the body by acids and it is only when the supply of base begins to fail that acidosis passes into acid intoxication. We know that a high degree of acidosis by the acetone bodies may exist for weeks and even for years, as in acute starvation and severe diabetes, without causing any symptoms of acid intoxication ; in fact, we do not know any condition whose symptoms and fatal issue are probably due to an acute acid intoxication, with the single exception of diabetic coma. Even in such a severe disease of the liver as acute yellow atrophy, although an acidosis is certainly present, death supervenes far too rapidly for the symptoms to be due to the acidosis passing into an acid intoxication. This is still more obviously true of poisoning by phosphorus, in which the acidosis is less severe. It is further remarkable what severe and widespread changes may exist in the liver without causing acidosis. For instance, in poisoning by hydrazine, which induces changes in the liver similar to those of phosphorus, no acidosis is present; and the same is true of animals in which multiple necroses of the liver have followed the injections of hæmolytic sera. From these con. siderations we have to conclude that alkalies could not be of much value in the treatment of delayed chloroform poisoning and clinical experience confirms it.

The weight of evidence is in favour of the view that the poisoning by chloroform is the cause not only of the symptoms but also of the microscopical changes found in these cases. It is, however, manifestly necessary to believe that certain individuals are highly susceptible to the action of chloroform, and the cause of this state of things is equally unknown, no matter whether we call it idiosyncrasy or believe that the vitality of their protoplasm has received some previous injury which has made it unduly susceptible to the action of a general protoplasmic poison like chloro. form. Numerous experiments on animals have shown that the action of chloroform on cells is similar to that of phosphorous, arsenic, and other general protoplasmic poisons. Although we do not know how any of these poisons injure cells it is necessary to form some working conception of what changes they induce in the metabolism of the body in addition to the changes caused by the concomitant starvation. The broad facts seem to be as follows. Nitrogenous metabolism is increased-that is to say, there is an increased breaking down of tissue proteid. But the metabolism of nitrogenous substances is also disturbed so that products of proteid catabolism leave the body no longer in a fully oxidised state; consequently the cells have lost to a corresponding degree the power of obtaining energy from proteid. The hepatic glycogen rapidly disappears and to a less extent that of the muscles and other cells; and further the total quantity of carbohydrate in the body is decreased. But in poisoning by chloroform the liver has not necessarily lost the power of forming glycogen, as can be shown by feeding the animals with dextrose. It is therefore clear that carbohydrate metabolism is increased greatly at first and that since the store of carbohydrate material in the body is relatively very small, this increased utilisation must soon come to an end. The facts in regard to the metabolism of fat are well estab. lished. Microscopically the cells of the liver, muscles, and kidneys appear to be loaded with fat. In the case of the kidney, however, there is no actual increase of fat; the appearance of the cells is due to a change in their protoplasm whereby fat in combination and thereby masked and invisible becomes obvious under the microscope. In the liver and muscles there is an actual increase of fat which has been transported in the blood from the normal sites of storage and has been taken up by the cells of these tissues. A similar active transference of fat from the depôts to the hungry cells takes place in starvation, but in this case the cells of the liver and muscles do not become loaded with fat; and this must be because they can metabolise it more rapidly. In poisoning by chloroform the cells are starving and call for fat which they take up more greedily than they can metabolise it ; and hence, whilst the transference of fatabout the body is increased, the metabolism of fat is decreased and we observe under the microscope a fatty infiltration of degenerated prote plasm.

These are the broad facts ; and Rosenfeld's interpretation of them has been hinted at and may now be shortly stated. He believes that when cells are poisoned by chloroform their metabolism is so altered that whilst they can utilise carbo hydrates well they can oxidise proteids but imperfectly and 
fats even less well. Consequently as soon as the cells have used up their meagre store of carbohydrate, their hungry condition causes a breaking down of tissue proteid and a transference of fat to them; but since neither of these foodstuffs, and especially the fat, is properly utilised, the cells remain in a condition of severe starvation which may rapidly lead to their death through lack of energy. He and other observers have shown that if the poisoned animal is fed with dextrose the transport of fat is prevented because it is no longer necessary ; and further, that recovery is much more likely to take place than when the animal is starved. Feeding with carbohydrates, of course, does not prevent the poison from damaging the cells, and it has been found to be useless when protoplasm has been too severely damaged, as in acute poisoning by phosphorus, but carbohydrates do provide the cells $w$ ith the source of energy which they can most easily atilise, and may therefore prevent their dying from acute inanition and so give them time in which to recover.

If Rosenfeld's theory is accepted as the best working hypothesis of the changes in metabolism induced by chloroform the application of it to man is obvious. It would seem worth while to try feeding such patients with dextrose either by the mouth, or failing this by enemata or continuous rectal infusion of a 10 to 20 per cent. solution, or even by infusing intravenously a 6 per cent. solution. Since these cases are rare and since there is at present no means of knowing which patients will show a great susceptibility to chloroform, it is not likely that it will be possible to decide in man whether feeding with dextrose before the anasthesia is of any value, but it might be advisable to try it in rickety and ill-nourished children. And, further, it might be possible by inquiry to find out whether an abnormal susceptibility to chloroform is associated with an absence before the operation of such food as will keep up the store of glycogen in the body and whether conditions which reduce this store increase the susceptibility. For it seems clear from experiments upon animals that every chloroform anæsthesia must induce some change in the metabolism and yet the vast majority of patients do not exhibit the serious symptoms of delayed chloroform poisoning.

Seymour-street, W.

\section{A CASE OF CYSTIC DISEASE OF THE MAXILLARY ANTRUM.}

BY RICHARD LAKE, F.R.C.S. ENG., SURGEON TO THE ROYAL EAR HOSPITAL, DEAN-STREET, SOHO,
LONDON, W.

THE case about to be described is one that had been under my care at intervals during the last six years and was brought to me by Mr. E. T. M. Tunnicliffe of Finchley.

The patient, a female, aged 18 years, had had five years previously a nasal polypus removed by another surgeon. On Jan. 27th, 1902, when she was first seen by me, the history was that right nasal obstruction had been observed for about a year. On the right hand side a choanal polypus was seen in the post-rhinoscopic mirror and another portion was also visible by anterior rhinoscopy. This was removed by a snare with the patient under anæsthesia and it turned out to be a long thin bilobed choanal (antral) polypus. From this time the patient felt no discomfort in the nose until April, 1905, when she returned with a further obstruction of the right nostril and marked insomnia. On examination nothing was visible at the anterior nares, but a large and extremely translucent polypus was observed occupying the same situation as the former one, though of somewhat greater bulk. A short time afterwards the patient was admitted into a home to have this polypus removed, but during the previous night she had been startled by a tremendous rush of clear fluid from her nose, with complete relief of all the symptoms. Under the anæsthetic, however, a thin, empty cyst-wall was found and removed. The polypus in this case had obviously been cystic. Early in 1906 a second cystic choanal polypus had formed. This was also removed, followed by a considerable flow of fluid. Six months laterthat is to say, in July, 1906-a further small cystic polypus was removed under cocaine, obviously coming from the antrum, although there had been no doubt that all the previous polypi had sprung from this situation. About this time the patient began to exhibit signs pointing to pulmonary tuberculosis--that is to say, she lost flesh and suffered somewhat from night sweats and also had a certain amount of congh, but no bacilli were found in the sputum. Althongh the idea of clearing out the right maxillary antrum was mooted it was postponed, trusting that the tendency to cyst formation might have ceased. As, however, twice during 1907 cystic antral polypi were removed, on Nov. 5th, 1907, the antrum was opened through the canine fossa and the mucous membrane as far as possible was ablated. One large portion, occupying the floor and part of the anterior wall, was removed intact and was found to be closely studded with small cysts containing a straw-coloured fluid, the cyst-walls being extremely thin. The antrum was very roomy. An nninterrupted recovery followed.

The latest paper which I can find on the subject is by Bichaton ${ }^{1}$ who gives a précis of the literature on the subject. The chief difficulty has arisen from the want of accurate pathological details. Alexander (1897) has had, or seems to have had, the opportunity of examining and reporting upon cases which come under the same category as the present case, for he describes a triple origin for cyst of the antrum, dilatation (a) of lymphatic canals, (b) of blood-vessels, and (o) hypertrophy of the connective tissue. Later Hajeck (1899) proceeded to show that mucocele was a cystic formation proceeding from the mucosa of the sinus. This condition was described in a thesis by Geraldés in 1851. Amongst the various affections which have been grouped together as cystic disease of the antrum according to Jacques and Berteimes (1901) are : (1) development of posterior dental cysts; (2) prolonged and complete occlusion of the ostium (mucocele), the contents sometimes serous, sometimes hæmorrhagic ; and (3) cysts arising from the mucosa, fluid viscid and gelatinous.

In the case here reported the cysts were formed from dilated lymphatics. The fluid was serous, either pale straw coloured or colourless. The ostium was very patent. The points of chief interest were the connexion between polypus formation and cyst formation and the development of the pseudo-tubercular state, the latter being a not uncommon condition in polypoid degeneration of the nasal mucosa, and according to Waggett ${ }^{2}$ in antral suppuration.

Harley-street, W.

\section{LYMPHANGIOPLASTY :}

A NEW METHOD FOR THE RELIEF OF THE BRAWNY ARM OF BREAST.CANCER AND FOR SIMILAR CONDITIONS OF LYMPHATIO CEDEMA.

BY W. SAMPSON HANDLEY, M.S. LOND., F.R.C.S. ENG., HUNTERIAN PROFESSOR, ROYAL COLLEGE OF SURGEONS OF ENGLAND; ASSISTANT SURGEON TO THE MIDDLESEX HOSPITAL; SURGEON TO THE BOLINGBROKE HOSPITAL, WANDSWORTH COMMON, S.W.

(Preliminary Note.)

AMONG the complications of breast-cancer none is more terrible than the brawny swelling of the arm which frequently comes on in the later stages of the disease. The pain to which it gives rise is so excruciating that amputation has been suggested and frequently carried out for its relief. Incisions into the swollen limb have been employed with temporary benefit. No other remedy except the use of narcotics has been suggested. Apart from actual pain and consequent insomnia the discomfort and misery produced by the constant leaden drag of the paralysed, inflexible, and bolster-like limb are important factors in the sum total of misery produced by the disease.

The brawny arm occurs in about one case out of every six of breast-cancer. It was formerly considered to be due to the pressure of a mass of growth upon the axillary veins and this view is still stated with approval in some current textbooks. There are certain facts which go to show that this theory is untenable. During the operation for breast-cancer ligature or excision of the axillary vein bas frequently been done without the subsequent production of any cedema of the arm. Moreover, the brawny arm often occurs in cases which present no mass of axillary growth, but is rather associated with atrophic forms of the disease. Lastly, the teaching of pathology is that solid forms of cedema are not produced by simple venous obstruction acting alone.

1 Revue de Laryngologie, 1906, vol. i., p. 71. L 3 